\section{Febrile illness due to a parvovirus}

A short febrile illness in two patients was accompanied by the presence of a parvovirus in their blood, and afterwards they developed antibody to it. This virus has not been associated with symptoms, although it has occasionally been found in sera being screened for hepatitis-B surface antigen ( $\mathrm{HBsAg}$ ) and antibody to it is common in blood donors.

\section{Case reports}

(1) A 19-year-old soldier presented 11 days after returning from Gambia and nine days after being tattooed. He gave a history of nocturnal sweating and feeling hot and cold for a week and a dry cough and pain in the right hypochondrium for two days. His temperature was $37.8^{\circ} \mathrm{C}$ and his liver, which was just palpable, was tender. After admission he had a rigor and developed a tender occipital lymph node (which was palpable throughout seven months' follow-up). His dry cough persisted for a week and his sweating for three weeks. Investigation showed haemoglobin $15.5 \mathrm{~g} / \mathrm{dl}$; white blood cell count (WBC) $3.1 \times 10^{9} / 1\left(3100 / \mathrm{mm}^{3}\right)$ with $64 \%$ neutrophils, $20 \%$ lymphocytes (some reactive), $16 \%$ monocytes; erythrocyte sedimentation rate (ESR) $1 \mathrm{~mm}$ in first hour; normal liver function tests; and negative serological results in Paul-Bunnell, Widal, brucella, fluorescent treponemal antibody, cytomegalovirus, rubella IgM, and toxoplasma dye tests. Malarial parasites were not seen in thick films and the chest radiograph was normal.

(2) An 18-year-old soldier in the same unit as the previous patient presented feeling unwell and feverish 11 days after returning from Gambia and nine days after being tattooed. The only physical abnormality was a fever of $37.7^{\circ} \mathrm{C}$, which persisted for 24 hours. He remained well over the next seven months. Initial investigation showed haemoglobin $13.1 \mathrm{~g} / \mathrm{dl}$; WBC 3.6 $\times 10^{9} / 1\left(3600 / \mathrm{mm}^{3}\right)$ with $55 \%$ neutrophils, $23 \%$ lymphocytes (many reactive), $19 \%$ monocytes, $2 \%$ eosinophils, $1 \%$ basophils; ESR $3 \mathrm{~mm}$ in first hour; and the same range of negative test results as in case 1 .

The patients' day 2 sera reacted in counter-current immunoelectrophoresis (CIE) tests with one of two human serum reagents $(\mathrm{Pi}$ and $\mathrm{Sz}$ ) that contained antibody to $\mathrm{HBsAg}$. Other tests for $\mathrm{HBsAg}$, by reverse passive haemagglutination and radioimmunoassay, gave negative results. The day 2 sera also reacted in CIE with sera collected in convalescence (table). On electron microscopy the CIE precipitin lines formed by both patients' day 2 sera contained parvovirus-like particles, and in gel immunodiffusion (ID) tests they and a parvovirus B19-containing serum both reacted with the day 208 sera to give a line of identity.

\section{Comment}

In both patients an acute parvoviraemia was accompanied by a febrile illness which was followed by the development of antibody to the parvovirus present in their serum on the second day after presentation and to parvovirus B19. Although $30 \%$ of 261 English blood donors ${ }^{1}$ and over $40 \%$ of 3000 Australian donors (Cossart, personal communication, 1979) have antibody to the virus, this is the first report of a symptomatic parvovirus infection. The absence of reports of symptoms due to parvoviraemia when antibody is so prevalent suggests that the infection is usually asymptomatic and the viraemia transient. The mode of spread of the virus is unknown, though in this instance it may have been due to tattooing.

This parvovirus is likely to be detected only when CIE or ID tests with human serum reagents are used-for instance, to screen sera for HBsAg. More specific and widely available serological tests may show that its role in acute febrile illnesses has been underestimated.
We thank Dr P A Emerson for permission to report on these patients under his care, and Mr A A Porter for the electron microscopy.

${ }^{1}$ Cossart YE, Field AM, Cant B, Widdows D. Parvovirus-like particles in human sera. Lancet $1975 ; \mathrm{i}: 72-3$.

(Accepted 14 March 1980)

Department of Medicine, Westminster Hospital, London SW1

J M SHNEERSON, DM, MRCP, senior registrar

Virus Reference Laboratory, Central Public Health Laboratory, London NW9

P P MORTIMER, MD, MRCPATH, consultant

ELISE M VANDERVELDE, MB, DIPBACT, senior medical microbiologist

\section{Persistence of antibody 10 years after vaccination with Wistar RA27/3 strain live attenuated rubella vaccine}

The duration of immunity elicited by rubella vaccines administered in childhood is extremely important. Mass revaccination of women who have been primarily vaccinated in childhood is to be avoided, since the vaccine is contraindicated in pregnancy and in women who may become pregnant during the ensuing three months. Furthermore, this population group is not readily accessible for revaccination. To ensure protection during pregnancy vaccination carried out before the age of 13 years should confer immunity for at least three decades. The quality and durability of immunity elicited by rubella vaccine have been questioned. ${ }^{2}$

We report the results of a 10-year follow-up study of antibody titres in 20 girls who took part in the first comprehensive study of transmissibility of Wistar RA27/3 strain live attenuated rubella vaccine ${ }^{3}$. The results of titrating sera collected two and six years after vaccination have been reported. ${ }^{4}$

\section{Materials, methods, and results}

Venous blood samples were collected in August 1978 from 20 of the 21 initially seronegative girls vaccinated in 1968. Eight of these 20 had been revaccinated in school immunisation programmes during 1970-8. The sera collected in 1978 were titrated for haemagglutination inhibition antibody according to standard procedures in parallel with sera collected 46 days after vaccination in 1968 (or alternative sera-see table). The sera had been stored at $-20^{\circ} \mathrm{C}$ and were treated with manganous chloride and heparin to remove non-specific inhibitors before titration. Sera collected 46 days after vaccination were no longer available for four subjects, for whom samples collected two years (three subjects) or six years (one subject) after vaccination were substituted. Haemagglutination inhibition antibody titres of sera collected after vaccination in 1968 and in 1970 or 1974 were identical for three subjects but had decreased fourfold in one (case 12).

Titrations for neutralising antibody were carried out on the sera collected in 1978 from the 12 girls who had not been revaccinated (Dr D Horstmann, department of epidemiology and public health, Yale University School of Medicine).

Counter-current electrophoresis reactions of sera from two patients (case 1, case 2) with parvovirus infection at various days after presentation, two sera containing anti-HBs $(P i, S z)$, and serum containing parvovirus $B 19$

\begin{tabular}{|c|c|c|c|c|c|c|c|c|c|c|c|c|c|c|}
\hline & & & \multicolumn{12}{|c|}{ Sera reacting as antibody } \\
\hline & & & \multirow[b]{2}{*}{$\mathbf{P i}$} & \multirow[b]{2}{*}{ Sz } & \multicolumn{2}{|c|}{ day 4} & \multicolumn{2}{|c|}{ day 13} & \multicolumn{2}{|c|}{ day 20} & \multicolumn{2}{|c|}{ day 48} & \multicolumn{2}{|c|}{ day 208} \\
\hline & & & & & Case & $\begin{array}{c}\text { Case } \\
2\end{array}$ & $\begin{array}{c}\text { Case } \\
1\end{array}$ & $\underset{2}{\text { Case }}$ & Case & $\underset{2}{\text { Case }}$ & $\underset{1}{\text { Case }}$ & $\underset{2}{\text { Case }}$ & Case & Case \\
\hline \multirow{5}{*}{ 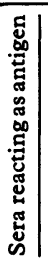 } & \multirow{5}{*}{$\begin{array}{l}\text { के } \\
\text { के } \\
\text { के }\end{array}$} & $\sim$ Case 1 & + & - & - & - & - & - & + & + & + & + & + & + \\
\hline & & - Case 2 & + & - & - & - & - & - & + & + & + & - & + & + \\
\hline & & $m$ Case 1 & - & - & NT & NT & NT & NT & NT & NT & NT & NT & NT & NT \\
\hline & & $\sim$ Case 2 & - & - & NT & NT & NT & NT & NT & NT & NT & NT & NT & NT \\
\hline & & B19 & + & - & - & - & - & - & + & + & + & + & + & + \\
\hline
\end{tabular}


Antibody persistence in stored sera-On testing in 1978 the geometric mean titre of haemagglutination inhibition antibody in the 16 sera collected 46 days after vaccination and still available for retitration was 64.4 , compared with 128.8 originally; five samples $(31 \%$ ) showed a fourfold fall in titre (table). This was probably due to loss of antibody during storage and not to the different methods of removing non-specific inhibitors (acid-washed kaolin in 19u8, manganous chloride and heparin in 1978).

Antibody persistence after vaccination-All sera had detectable haemagglutination antibody 10 years after vaccination (table). Antibody titres had fallen fourfold in four $(20 \%)$ subjects (three of the 12 not revaccinated and one of the eight revaccinated) and had increased fourfold in one of the revaccinated subjects. Neutralising antibody was present in all 12 subjects not revaccinated, at titres of 1 in 32 (three subjects), 1 in 8 (five), and 1 in 4 (four).

Titres of haemagglutination inhibition antibody in sera collected 46 days after vaccination in 1968 (tested in 1968 and 1978) and 10 years after vaccination. (Subjects in cases 13-20 were revaccinated between 1970 and 1978)

\begin{tabular}{|c|c|c|c|}
\hline \multirow{2}{*}{$\begin{array}{l}\text { Case } \\
\text { No }\end{array}$} & \multicolumn{2}{|c|}{ Sera obtained 46 days after vaccination* } & \multirow{2}{*}{1978 sera* $^{*}$} \\
\hline & 1968 & 1978 & \\
\hline 1 & 320 & 320 & 80 \\
\hline 2 & 160 & $80^{\circ}$ & 20 \\
\hline 3 & 160 & 80 & 40 \\
\hline 4 & 320 & $80^{+}$ & 40 \\
\hline 5 & 40 & 40 & 40 \\
\hline 6 & 160 & 40 & 20 \\
\hline 7 & 160 & 80 & 40 \\
\hline 8 & 160 & 160 & 80 \\
\hline 9 & 160 & 80 & 20 \\
\hline 10 & 40 & 40 & 20 \\
\hline 11 & 320 & 80 & 80 \\
\hline 12 & 160 & $20_{+}^{+}$ & 20 \\
\hline 13 & 160 & $80^{+}$ & 40 \\
\hline 14 & 40 & $160^{+}$ & 40 \\
\hline 15 & 160 & 40 & 20 \\
\hline 16 & 320 & 80 & 160 \\
\hline 17 & 80 & 20 & 80 \\
\hline 18 & 80 & 40 & 40 \\
\hline 19 & 160 & 80 & 80 \\
\hline 20 & 40 & 40 & 40 \\
\hline $\begin{array}{l}\text { Geometric } \\
\text { mean titre }\end{array}$ & $129 \cdot 9$ & $65 \cdot 0$ & $41 \cdot 4$ \\
\hline
\end{tabular}

*Titrated in parallel.

In four cases sera obtained in 1968 were no longer available, so tsera obtained in 1970 and + sera obtained in 1974 were substituted.

\section{Comment}

The duration of immunity elicited by a single dose of rubella vaccine is still a major issue. Our results show that haemagglutination inhibition and neutralising serum antibodies were present in all subjects 10 years after vaccination with the Wistar RA27/3 strain, but titres in several subjects were low and there might be cause for concern if they fell further. In sera collected soon after vaccination, loss of antibody with storage may cause the extent to which antibody has waned to be underestimated when these and recently collected sera are titrated in parallel.

The peak childbearing age is 29 in the Irish Republic and 26 in England and Wales. Thus if revaccination of women is to be avoided vaccine administered at about the age of 12 should elicit immunity for at least three decades. Clearly, better definition of these issues is needed, including a follow-up of further groups of subjects vaccinated for 10 years or more.

${ }^{1}$ Balfour HH, Amren DP. Rubella, measles and mumps antibodies following vaccination of children. Am $\mathcal{F}$ Dis Child 1978;132:573-7.

${ }^{2}$ Best JM, Harcourt GC, O'Shea S, Banatuala JE. Rubella vaccine. Lancet 1979;ii:690-1.

${ }^{3}$ Hillary IB, Meenan PN, Griffith AH, Draper CC, Laurence GD. Rubella vaccine trial in children. $\mathrm{Br}$ Med f 1969;ii:531-2.

* Hillary IB. Persistence of antibody after subcutaneous vaccination with Wistar RA27/3 rubella vaccine. 7 Hyg (Camb) 1971;69:369-72.

${ }^{5}$ Hillary IB, Freestone DS. Persistence of antibody induced by rubella vaccine (Wistar RA27/3 strain) after six years. F Hyg (Camb) 1975;75: 407-11.

(Accepted 24 March 1980)

Department of Medical Microbiology, University College, Dublin

I B HILLARY, MD, FRCPATH, lecturer

Wellcome Research Laboratories, Langley Court, Beckenham, Kent A H GRIFFITH, MD, FFCM, deputy director of clinical research

\section{Prostacyclin in pregnancy}

Stable prostaglandins have physiological roles in pregnancy, but the recently discovered unstable eicosanoids thromboxane $A_{2}$, prostacyclin $\left(\mathrm{PGI}_{2}\right)$, and the leukotrienes ${ }^{1}$ have not been studied in pregnant women. Using a new gas chromatography-mass spectrometry assay we have measured the stable hydration product of $\mathrm{PGI}_{2}, 6$-oxo-PGF $\mathrm{P}_{1 \alpha}$ in the plasma of pregnant women. Platelet aggregability was also measured.

\section{Patients, methods, and results}

Five groups were studied: 18 non-pregnant women, eight women taking oral contraceptives, six women in early pregnancy ( 8 to 15 weeks), nine women in late pregnancy ( 28 to 39 weeks), and seven women one to seven days after delivery. No patient had taken aspirin-like drugs within seven days of the study. The outcome of all the pregnancies was normal.

Blood was drawn without stasis and the heparinised blood rapidly centrifuged at $4{ }^{\circ} \mathrm{C}$ in the presence of indomethacin $0.01 \mathrm{mmol} / 1$. Plasma 6 -oxo$\mathrm{PGF}_{1} \alpha$ was assayed by gas chromatography-mass spectrometry. ${ }^{2}$ The lower limit of sensitivity was $62.5 \mathrm{pg} / \mathrm{ml}$. The coefficient of variation at this concentration was $11 \%$. A further blood sample was citrated and platelet-rich plasma obtained within one minute using ultracentrifugation (Eppendorf). The minimum dose of adenosine diphosphate (ADP) causing irreversible platelet aggregation was determined (Payton aggregometer).

The plasma 6-oxo- $\mathrm{PGF}_{1} \alpha$ concentrations were similar in all patients except in late pregnancy and the puerperium, when the levels were almost double those in non-pregnant women (table). Women in late pregnancy and the puerperium also had significantly more aggregable platelets. The mean concentration of 6 -oxo-PGF $1 \alpha$ in non-pregnant women was similar to that in healthy men of similar age.

Mean $( \pm S D)$ plasma concentrations of 6 -oxo-PGF $\alpha$ and platelet aggregability in five groups of patients

\begin{tabular}{|c|c|c|c|c|}
\hline Patient group & & No & $\underset{ }{\text { Plasma }} \underset{(\mathrm{pg} / \mathrm{ml})}{\text { oxo-PGF }}$ & $\begin{array}{l}\text { Minimum ADP } \\
\text { concentration } \\
\text { for irreversible } \\
\text { aggregation } \\
\quad(\mu \mathrm{mol} / 1)\end{array}$ \\
\hline $\begin{array}{l}\text { Non-pregnant } \ldots \\
\text { Non-pregnant on oral contraceptives } \\
\text { Early pregnancy ( } 12 \text { weeks) } \ldots \\
\text { Late pregnancy ( }>28 \text { weeks) } \\
\text { Puerperium }(-7 \text { days after delivery) }\end{array}$ & $\begin{array}{l}\cdots \\
\cdots \\
\cdots \\
\cdots\end{array}$ & $\begin{array}{r}18 \\
8 \\
6 \\
9 \\
7\end{array}$ & $\begin{array}{l}123 \pm 22 \\
138=26 \\
131=17 \\
244=133^{*} \\
227 \pm 108^{*}\end{array}$ & $\begin{array}{l}2.07 \pm 0.78 \\
2.65 \pm 0.71 \\
2.06 \pm 0.45 \\
0.58 \pm 0.54^{*} \\
0.61 \pm 0.48^{*}\end{array}$ \\
\hline
\end{tabular}

*Significant difference from mean value in non-pregnant women $(p<0.001$, Students $t$ test $)$.
$\mathrm{ADP}=$ Adenosine diphosphate

\section{Comment}

We have shown a high concentration of plasma 6-oxo-PGF $1 \alpha$ in late pregnancy. The concentration of $6-0 x-\mathrm{PGF}_{1 \alpha}$ measured in plasma in vitro probably reflects the circulating concentration of active prostacyclin. Prostacyclin is unstable and hydrolyses to 6-oxo-PGF ${ }_{1 \alpha}$ during extraction. In previous experiments we have shown a parallelism between concentrations of this hydration product and expected changes in circulating prostacyclin. Prostacyclin is a circulating hormone with a potent platelet inhibitor action. A balance probably exists between proaggregatory thromboxane production in platelets and antiaggregatory prostacyclin production by vascular endothelium. ${ }^{1}$ Our results show that this balance is disturbed in late pregnancy since prostacyclin concentrations are high but the platelets are hyperaggregable. The platelet results accord with the clinical experience that thromboembolism is more common in women at this time. The source of the increase in prostacyclin is not known. The main source of circulating prostacyclin in non-pregnant adults is the pulmonary circulation. ${ }^{3}$ During pregnancy the placenta and uterus might each contribute prostacyclin since both generate prostacyclin in vitro.4 High concentrations of $6-0 x 0-\mathrm{PGF}_{1 \alpha}$ have been detected in human amniotic fluid. Human umbilical blood vessels are more active in synthesising $\mathrm{PGI}_{2}$ than are adult blood vessels ${ }^{5}$ so that the fetus might be a source, but the high concentration of 6-oxo-PGF $1 \alpha$ post partum makes this less likely.

What role might prostacyclin have in pregnancy? It might be concerned in the characteristic vasodilatation. Increased prostacyclin production might be an adaptive response to a primary increase in platelet aggregability. Platelet consumption is an early feature in preeclampsia and a major component of disseminated intravascular coagulation, a serious complication of late pregnancy. In these 